combination surprise us, since we know that the cerebral aress ntilized for the storage of the visual memories of words and figures, though distinct, are close together, and hence may be sometimes simultaneously involved, as in the present case.

In the discussion that followed the reading of $\mathrm{my}$ paper on hereditary congenital word-blindness at the Exeter meoting in 1907, Mr. Sydney Stephenson narrated a striking example of six cases of congenital word. blindness affecting three generations of one fami $y$, which he subsequently published. ${ }^{4}$ Mr. T. Herbert Fisher ${ }^{5}$ also published a case of congenital wordblindness, and in his paper called special attention to the fact that the ancle of the child had also experienced the greatest difficulty in learning to read. The evidence is thus gradually increasing as to the hereditary tendency in congenital word-blindness. I have little doubt that in future, if observers in every case would make careful inquiries into the family history both of the present and previous generations; the evidence would rapidly increase as to the frequency of this hereditary tendency.

The fact that congenital word-blindness is sometimes hereditary, as is typically exemplified by these six cases occurring in two generations of the same family, is of some importance from the etiological standpoint. In my paper on congenital word-blindness at the Oxford meeting of the British Medical Association in $1904,{ }^{6}$ I said that in these children their difficulty in learning to read can most readily be explained on the ground of some defect in the special area of the brain, generally the left angular gyrus, where are stored the visual memories of words and letters, and that if there be any abnormality within this ares; due either to disease, to injury at birth, or to faulty develop. ment, it was easily conceivable how such children should experience abnormal difficulty in learning to read. In these six cases belonging to the same family and other hereditary groups it is evident that the abnormal condi tion of the visual memory centre is a matter of faulty development, and it is probable that in most cases of congenital word.blindness the condition is the result neither of disease nor injury at birth, but of defective development of this definite cerebral area occurring in the early stages of embryonic growth. This view, that congenital word. blindness is the result of faulty development and not of disease or injury, derives considerable farther support from the fact that homonymous hemianopsia, which is so frequently associated with acquired word-blindness, has never been met with in any case of congenital word-blind ness. In a paper of mine on word.blindness with right homonymous hemianopsia ${ }^{6}$ I discuss the reason for the frequency of this combination, and have in my own ex. perience met with five cases of acquired word-blindness associated with right homonymous hemianopsia. The fact that this association, so frequently observed in acquired word-blindness due to cerebral disease, has never yet been met with in the congenital form is important and significant.

With regard to the future of these two cases of congenital word.blindness, I have no doubt that both children can be taught to read. In the case of the girl, she has already, although very slowly, made definite progrese, and this will be much accelerated if she is taught in the proper way. Even in the case of the boy, where little progress has been made after being fou years ut school, I am certain be can be taught to read if the task be undertaken in the proper way and with sufficient persistence and perseverance. For my views on the proper method of teaching these cases I would refer to my two previous papers on this sabject in the British Medical Journal. ${ }^{1} 6$

Of the many cases of congenital word-blindness which I have seen all have ultimately been taught to read. But it is to be observed that by congenital word.blindness I mean pare cases, where this defect exists alone in an otherwise healthy and normal brain. Cases of inability to learn to read associated with general defective intel ligence and defect of other cerebral centres belong to quite another category, and in saoh cases the prognosis is not so hopoful.

Pare congenital word.blindness, which is a local affection of a limited cerebral area, can always be overcome by perseverance and proper methods of education, and herein lies the great importance of the recognition at an early period of the true character of such cases.

Thinshelwood, REFrReNCEs.

I Hinshelwood, British MEDICAL JoURNAL, November 2nd, 1907. 2 Thomas, Ophthalmic Review, August, 1907 . 3 Binshelwood, Letter, Word, and Mind Blindness, London, H. K. Lewis, 1500. isyaney Stephenson, Ophthalmoscope, September, 1907. 5 Fisher, Ophthalmic Review, November, 1905. 6 Hinshelwood, BRITISH MEDICAL JOURNAL

\section{AN EPIDEMIC OF INFANTILE PARALYSIS IN BRISTOL.}

By GEORGE PARKER, M.D.CAMB., PHYBICLAN, BRIBTOL GENERAL HOBPITAL.

The spread of infantile paralyk is in an epidemic form during the last few years over a great part of Europe and America has been so extraordinary, and the outlook for the fature is so serious, that I need hardly apologize for bringing before you the facts of an outbreak in Bristol from June, 1909, to January, 1910. It is one of the first which have occurred in Evgland. W. W. Treves reported a group of 8 cases in 1908, and in 1910 some 13 were recorded at Maryport. The cases which I have collected by the kind help of friends and colleagnes number 37. I have seen nearly all of them myself, and examined their present condition. If the numbers are small compared with those of some foreign epidemics, they are, I think, quite enough to show that we have more than the sporadic form of the dicease to deal with. Happily we have not yet reached the condition of the United States. where Flexner estimates that 20,000 cases occurred during the last summer.

I could find hardly any cases here in the first months of 1909. In June 5 appeared, and 27 more by the end of October, leaving 5 only during the next thrce winter monthe. The usual time is during the three summer months, and it is curious that our attacks should go on past mid-winter. The summer, too, had been cold and wet with us.

The age of the patients varied from 4 months to $16 \frac{1}{2}$ years, giving an average age of 3 years, or if we omit three adolescents the average age of the rest was almost exactly 2 years. There were 24 males and 13 females,

Gowers has remarked that in the epidemic, as distinct from the sporadic, type there are a considerable number of complete recoveries without paraly sis, that the mor. tality is considerable, perhaps 10 or 12 per cent., because fatal bulbar and cerebral attacks are recognized as due to this disease, and that adults suffer as well as children. As our statistics were collected after the outbreak, and as public attention was not directed to poliomyelitis at the time, it is probable that most of these abnormal cases were overlooked. I have not included in my list any cases where paralysis was absent throughout. On the other hand, I cannot point to any absolutely complete recovery, though three or four are practically well. The great majority are more or less crippled for life. Two patients died, a mortality of nearly 6 per cent.

Most of the children had a febrile attack before or imme. diately after the onset of paralysis. In about a quarter of them pains of a rheumatic character are recorded. In one child the knee was kept flexed for some days as if from joint pain, a symptom which I bave seen belore. Some had pain down the spine, and in two retraction of the head was noticed, which might lead to the diagnosis of meningitis. Facial paralysis occurred in No. 2l. In view of Flexner's suggestion that the entrance of the infection is often through the naso.pharyngeal membrane, we may remark that tonsillitis appesed in two cases, Nos. 36 and 37 , and pulmonary troubles in several, such as Nos. 8, 20, and 25, whilst in three there were symptoms of measles-Nos. 15, 24, 36. How far the latter were real attacks of measles, which predisposed the patient to the infection of poliomyelitis, or merely symptoms of the latter disease, it is hard to say.

On the other hand, there were half a dozen children who were suddenly paralysed while apparently in perfect health-for example, 7, 11, 14, 21, 22, 31, 32. In otbers the history of a previous fall or blow was recorded. The importance of this is problematical. In one, the details of 
which are absent, the attack came on after a surgical injury.

The qu stion of how the infection is conveyed is an important one. There can be no doubt whatever of the existence of a transferable virus, since it has been conveyed to thirty or forty monkeys in succession, reproducing all the symptoms of the disease. The germ is ultra-microscopic, and can be obtained from the spinal cord of either a sporadic or epidemic case. But, as Flexner says, it is necessary to bring it into direct relation with the central nervous system; and the remarkable thing in most outbreaks is that while instances of direct contagion and of carriage by healthy persons are common, the vast majority of contacts show no symptoms. Whether this is due to insusceptibility, numerous abortive attacks, or to difficulties of the entrance of the organism, is not clear.

In different epidemics infectiousness varies enormously. In Sweden, at Trostëna, the infection of otherwise isolated families was clearly traced to a school. In Nebraska, Holt says there were six families with 2 children each attacked, five with 3 , three with 4 cases, and one with ali the 6 children in the house strack down. A boy was attacked nine days after the return of his mother and brother from a house in another town, in which house a child was suffering from it. On the other hand, at Vorpommern, in 51 cases with a 17 per cent. mortality, no case could be traced to any other. In some places instances of the long duration of infection in persons or houses seem clear. Indeed, the Massachusetts report for 1909, which is perhaps the most carefal and minute of any, mentions "for what it is worth" eleven instances where the disease followed intimate contact with old cases of infantile paralysis often of several years' standing.

In Bristol there was one family of eight children in which a boy was attacked severely and taken to the Royal Infirmary. The very next day a sister, who had had some previous bronchial trouble was found to be paralysed too. The other children seemed to have escaped. Again, Cases 1 and 31 were living a fow doors from one another, but one was attacked in July and the other in November. So, too, Cases 3 and 8, where the attacks came on in September and December. In the great majority of the children no connexion with other cases has been established. Thirty-four of them lived in an urben area stretching across the southern part of the city, and three in outlying districts. Most of thom were treated by massage and electric baths at the Royal Infirmary, the General Hospital, and the Royal Children's, and the Ortbopaedic Hospitals.

Cases of Infantile Paralysis in Bristol, June, 1909, to JANUARY, 1910

1. R. D., 2 years and 6 months, male, Lincoln Street, Barton Hiil, was attroked in November " with fever and vomiting, but no convulsions," and on the third day was paralysed in the left leg. There was no pain at any time. He can now (November, 1910) move the thigh and leg leebly, and to-day for the first time the toes are seen to be moved. The entire limb is wasted and the foot still cold and red. There is no knee-jerk on the left side. He lived a few doors from No. 31 . (Attended at Bristol General Hospital.)

2. K. W., 2 years and two months, male, Park Terrace, School Rosd, Totterdown, was in good heslth till suddenly on August 25th great weakness in the right leg come on. After this he became feverish, his head ached and could not be lifted from the pillow. He complained of pains all over for fourteen days. There was retraction of the head, but no loss of consciousness. The right thigh, leg, and loot were paralysed. He can now support himself upright for a few moments, and swing the right leg to and fro, but he has talipes calcaneus. There is no kneejerk on either side, and the left foot also is cold and bluish. (Attended at Bristol General Hospital.)

3. H. R., 13, female, Victoria Avenue, Redfield. The eldest brother died of pernicious anaemia six months before, all the other children were in good health. She was attending school and had recently passed an examination. On September 13th had pains all over which lasted for a week, and on the 15th was paralysed all over both in limbs and trank. This passed away except as to the left thigh and right foot, which were wasted and very feeble. There is no knee-jerk on either side. She lived a Dr. J. M. Clarke.)

4. F. S. M., 1 year and 3 months, male, Phœnix Street, Barton Hill, fell out of his mail-cart one day in June, and two days later was feverish and started in his sleep. The next day complete paralysis of the right thigh and leg come on. He then slept for two days and nights and finslly lost the use of the right arm also. The arm is now strong and the leg hes regained some power. He can walk a little alone. The peronei are still very feeble, the leg is blue and wasted, and there is no knee-jerk on that side, though it is present on the left. (Attended at Bristol General Hospital.)

5. A. M., 16 years 6 months, male, Clifton, was attacked with fever (temperstare $104^{\circ}$ ) on October 10th. Next day the temperature fell. For a week he had slight pains in his limbs, but went to school. On October 17th severe pain came on in the head and neck and paralysis of the left arm. The reflexes in this arm disappeared, but sensation was normal. There was no optic neuritis, but photophobia and epistaxis. On the 18th paralysis of the shoulder muscles of the right arm came on, and on the 22nd desth from respiratory failure-that is, bulbar paralysis. (Reported in the Lancet by Dr. Symes.)

6. D. G., 2 years 8 months female, Richmond Park Road, Clifton. Ön January 14th, 19i0, had headache and fever, and on the 16th was attacked by paralysis in both legs, with some pain. Afterwards the paralysis in the right leg below the knee became absolute, with the exceptlon of some movement in the toes. Knee-jerk absent. The paraly sis almost entirely passed away after some months, but the lo reme suffered from pavor wasted for a long time. For a while she suffered in fairly good nocturnus and mental irritability, but she is now in fairiy good 7. W. H., 2 years 5 months, male, South Road, Bedminster, was attacked on June 19th. The only symptom was weakness, and then complete paralysis of the right leg. There was no fever or other illness. He had always been in good health previously. The leg gradually improved, and he can now walk alone fairly well. The limb below the knee is red, wasted, and feeble. Knee-jerk little or none in either leg. (Attended at Bristol General Hospital.)

8. H. L., 1 year 2 months, male, Victoria Avenue, Redfield. Had no previous illness, but on December 11th was taken il with fever (temperature $102^{\circ}$ ), pains in the head, and pulmonary

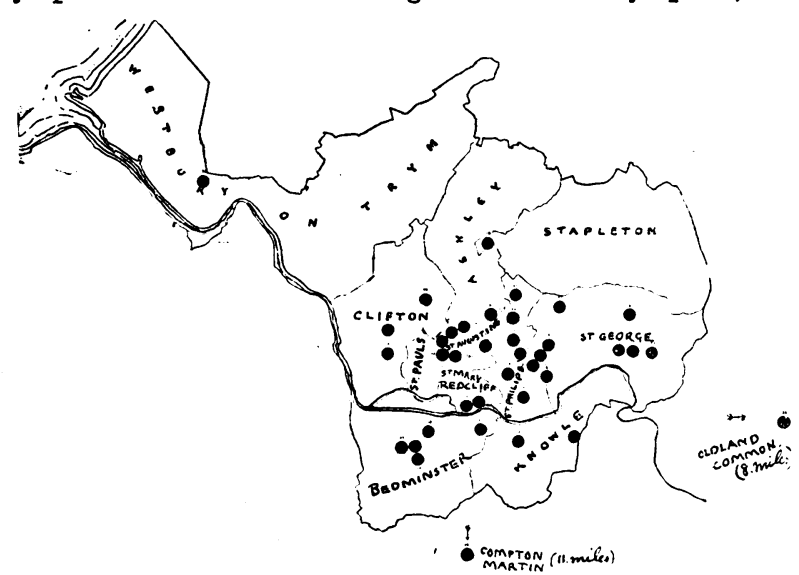

Map of the City and County of Bristol.

on December 22nd flaccid paralysis of all four limbs was noticed. There was a gradual recovery of power, but the muscles were wasted for some time. The knee-jerks were absent. This patient lived a few doors from No. 3. (Attended by Dr. Alexander.

9. A. G., 2 years 10 months, male, Tennyson Terrace, Speedwell Roed, St. George. In October he was found to be feverish, and complained of pains in the limbs. The head was retracted and the left leg became paralysed. In December, 1910, the left thigh, buttock, and leg were still wasted, and the muscles faccid ; the colour was normal, but till lately it was blue. The patient could just move two toes, but could not walk, even with crutches. (Attended by Dr. Foss, and at Bristol General Hospital

10. M. E., 1 year and 3 months, female, Stanley Terrace, West Street, Bedminster, was found to be feverish on June 23rd, and on the next day the left leg was paralysed. Later on the absence of the knee.jerk and of the reaction to faradism was noted. The foot could not be dorsiflexed, and there was no plantar reflex. The whole limb still remains cold and atrophied. Patient can walk very fairly, but the foot turns out nearly to a right angle. (Attended at Bristol General Hospital by Dr. Coombs.)

11. W. J., 2 years and 7 months, mole, St. Luke's Road, Bedminster, early in Angust was found to have partial paralysis of the right leg. The knee was at first contracted; no fever was apparent. He was admitted to the General Hospital and gradually improved. At the present time the thigh and leg are somewhat atrophied, but the knee-jerk is present and the patien walks very well. (Attended at Bristol General Hospital by Dr. Neild.)

12. F. H., 1 year, male, Cathay, Redcliffe, fell out of bed and bruised his left knee in the first week of September. No febrile attack was noticed. About September 19th, sudden paralysis of the right leg appesred. He had always been strong and hearty. Present state cannot be learnt. (Attended at Bristol hearty. Present state cannot be

13. E. W., 2, male, Victoria Avenue, Horfield, complained of pains all over on August 4th, and was found to be shivering. This went on for three weeks. About August 25th paralysis of the right leg was noticed. He recovered some power so as to be able to walk a little by October. There was no knee-jerk in 
either leg, and the right quadriceps femoris was wasted. The leg remained cold, and the foot dragged in walking. (Attended at Bristol General Hospital.

14. A. C., 4 months, male, Dean Terrace, Moorflelds, was attacked in August by paralysis of the left leg, but retained the power of moving the toes. There had been no fever or diarrhoea observed. When seen by a doctor there was wasting and and thigh were wasted, but not cold. He had foot-drop, but could walk two or three steps. The knee-jerk was present in both legs. (Attended at Bristol General Hospital by Dr. Neild.) 15. R. O. C., 1 year, male, Beaufort Street, Stapleton Road, suffered from an attack of "German measles" in September. Fourteen days later he was attacked with paralysis in all four limbs. The right leg was most affected, the left leg less so, and the hands least of all. The back muscles were also enfeebled. He now has complete use of his hands, moves both legs to and fro, but cannot stand. There is no knee-jerk present. His mother died from a tumour of the brain. (Attended at Bristol General Hospital.)

16. F. J., 4 years, male, Shepherd Street, St. Philips, became feverish July 24th. This lasted four days, and was followed on July 28 th by paralysis of the right leg. In September he was ing ; dorsiflexion of foot and toes very ; foot dragged in walkwas present. (Attended at Bristol General Hospital.

17. A. P., 2 years and 6 months, female, Sandown, Brislington was feverish for a week from June 24th, and complained of pain in the hip. About June 30th the left leg was paralysed. This gradually lessened, and she can now run about with a limp. The buttock and thigh are cyanotic and wasted; kneever weak (A peronei and common extensors of the

18. G. O., I year and 10 months, female, Colston Street Cathay, Redcliffe, was found to be feverish on Angust 17th and partially paralysed in both legs. Admitted August 19th. Tem perature $101^{\circ}$. Could stand with difficulty and could not walk Right leg wrs the worke; knee-jerk not present on that side, but normal on the left. Plantar reflex absent on right and extensor on left. August 20th: Temperature 98.4 ${ }^{\circ}$. Later on the right leg atrophied below the knee. She now walks fairly well, but the foot turns outwards. Knee-jerks are active on both sides. There is no blueness of the skin. (Attended at Bristol General Hospital by Dr. Parker.)

19. E. B., 12 years, male, Bedminster, was attacked in August and the right shoulder was paralysed. In September wasting of the shoulder girdle was found to have taken place. No detal

20. T. D., 1 year and 3 months, male, Pearl Street, Bedminster, was attacked in August with vomiting, fever and "pneumonia," which lasted six weeks. Paralysis of all four limbs. This gradually improved till in seven months he could stand with a little help. There was then complete paralysis of the extensors of the right foot only, with loss of the faradic reaction. The calf and other muscles were wasted; the leg was still cold and discoloured, and there was no knes-jerk on either side. (Attended by Dr. Murray Smith, and at Bristol General Hospital.)

21. J. W., 4 years, female, Henry Street, Barrow Street, had always good health till in August sudden weakness in both legs, especially the left, came on. There was no fever or diarrhoea; left facial paralysis was also noted but this cleared up. When seen in 1910 she could walk fairly well, but both legs were wasted to a marked degree and very cold but not discoloured. The knee-jerk was then

Attended by Dr. Finzel.)

22. B. J., 7 months, female, Penpole Place, Shirehampton, had no previous illness and no feverish attack at the onset. In September the left leg became partially paralysed, was flaccid, and began to waste. At the present time the leg is wasted and the foot cold ; knee-jerk present on both sides. (Attended by Dr. Burd, and at Bristol General Hospital.)

23. C. J., 3 years 3 months, male, Hillside Road, St. George, was said to have been attacked with fever and rheumatic pains in August, and then paralysis of all four limbs and back. The right leg seems to have been most affected, and showed the reaction of degeneration; knee-jerks were absent on both sides. (Attended by Dr. Blagg, Orthopaedic Hospital, and at Bristol Royal Infirmary.)

24. E. K., 1 year 8 months, Silver Street, City, was attacked with running at the eyes and nose and fever on September 10th. The next day the right leg was completely paralysed, and the patient could not sit up, and complained of pain in her back. There was gradual recovery, but for eight months she could not There was gradual recovery, but for eight months she could not
walk. The limb is still wasted and bluish, and the foot turns walk. The limb is still wasted and bluish, and the foot turns (Attended by Dr. Maddison.)

25. E. M., 1 year and 10 months, female, Dove Street, Kingsdown. In July had diarrhoea and then bronchitis. Her brother was attacked on August 7th, and on the 8th her right arm and leg were paralysed. Gradual improvement took place, and in November, 1910, she could stand up with assistance, but both ankles gave way in the attempt. The right thigh and leg were wasted, cold, and paretic, and the knee-jerk absent. The arms were normal, except that the forefinger of the right hand generally remained flexed when the others were extended. When lying down the foot-drop on both sides was very marked. (Attended at Royal Children's Hospital by Dr. Isavington.)

26. W. M., 2 years and 8 months, male, Dove Street, Kingsdown, was at play on August 2nd, and fell and knocked his head, He said that he felt giddy, his eyes twitched, he vomited twice, and remsined unwell. On August 7th he was paralysed in every pulse 120 , lungs fall of rofles. Complained of pain in the neck, pulse 120, lungs fall of rales. Complained of pain in the neck, and the head fell back and to the left side, if not supported Kernig's sign absent; no knee-jerk obtained. Plantar reflexes both extensor. Shoulder and upper arm muscles on both sides, except left triceps, showed reaction of degeneration when tested. Movement of arms and legs very feeble; noloss of sensation. slowly improved, and is now able to run about, and shows little trace of his illness. The arms recovered more slowly than the legs, and the neck last of all. There were six other children in the family besides this boy and his sister. (Attended at Bristol Royal Infirmary by Dr. Nixon.

27. L. M., 2 years and 6 months, female, John Street, Mina Road, wassuddenly paralysed in the left leg about September 25th. This was discovered in the morning when she got up. She was feverish, and after a week was admitted to the Royal Infirmary. At the present time the leg is wasted and cold, and there is no knee-jerk on that side. Bhe walks with difficulty, and cannot
dorsiflex the foot. (Attended at Bristol Royal Infirmary by dorsiflex the
Dr. Prowse.)

28. A. C., 5 years, female, Oldland Common, was taken ill about September 3rd, and was paralysed in the left shoulder, for which she was admitted to the Children's Hospital on October 10th. The paralysis passed away more or less completely. The patient has moved away, and her present condition cannot be discovered. (Attended at Royal Children's Hospital.)

29. M. F., 6 months, female, Compton Martin, in September had a feverish attack for one week, then paralysis of all four limbs. The left leg remains feeble, cold, and wasted. (Attended by Dr. Gough at Royal Children's Hospital.)

30. W. R., 1 year, male, Short Street, St. Philips, had a long attack of "bronchitis" in December, and in January the mother noticed that he was partially paralysed in the left leg and unable to "put his heels down to the ground." At the present time there is some wasting in the left leg, and the foot till lately turned out when walking and

31. A. F., 3 years, male, Lincoln Street, Barton Hill, went to bed quite well on July lst, but when the morning came the left leg below the knee was completely paralysed. There was no history of pain at any time. The leg below the knee is now wasted, cold, and blue. It is 2 in. less in circumference than the other and is 1 in. deficient in length. He can stand and walk a little, but the arch of the foot has given way and he cannot dorsiflex the foot. He lived a few doors from No. 1. Attended at Bristol Royal Infirmary by Dr. Stack.)

32. J. K., 2 years and 8 months, male, Harford Street, St. James, had always been healthy till in October the mother noticed that his left leg was partially paralysed. It is now wasted and cold, and there is no knee-jerk on that side. The arches of both feet have given way. but the boy runs about merrily. (Attended at Bristol Royal Infirmary by Dr. Nixon.) 33. D., male, address unknown, while attending as an outpatient for an injury to the elbow in January, 1910, was attacked with paralysis of the shoulder muscles, for which he was treated in the massage department. Present condition cannot be ascertained. (Attended at Bristol Royal Inflrmary by Dr. Stack.)

34. F. M.) 5 months, male, Hill Street, St. Paul's, was attacked with convulsions, diarrhoea, and sickness in August, and some time after was found to be paralysed in the left leg. The limb is still cold and wasted. The patient cannot stand alone, and there is no knee-jerk on the left side, though it is active on the right. (Attended at Bristol Royal Infirmary by Dr. Walters.)

35. C. S., 1 year and 4 months, male, Thomas Street, Stokes Croft, was said to have had a fall on June 13th, which was followed by convulsions. The next day he was paralysed in both legs and the back, and was taken to the infrmary. The temperature was $102^{\circ}$. The fundi oculi were normal. The knee-jerks were absent. The paralysis of the le affected. An examination of the spinal fluid showed polymorphonuclears, 26 per cent. ; lymphocytes, 68 per cent. ; and endothelial cells, 6 per cent. There was gradual improvement, but the left leg is still much wasted, and shows no knee-jerk. The patient
walks fairly well in an iron support. (Attended at Bristol Royal Inflrmary by Dr. Edgeworth.)

36. F. S., 5 years, female, Greenbank Road, St. Mark's, had always been healthy. She had a sore throat on October 17th and after three days' illness was admitted to the Royal Infirmary on October $20 \mathrm{th}$, found to be affected with paralysis. of all four limbs. The legs were completely paralysed, and the knee-jerks absent. On November 5 th tonsillitis occurred (no Loeffler bacilli), and on the 9th a rash like measles appeared with enlargement of the glands behind both ears and below the jaw. Bronchopneumonia followed, and the patient died on the 13th. The post-mortem examination showed typical lesions of acute anterior poliomyelitis. (Attended at Bristol Royal Infirmary by Dr. Edgeworth.)

37. R. S. F., 3 years and 5 months, male, Alexandra Park, Redland. was always well and active till on August 14th he became drowsy and feverish. About four days later the right leg was paralysed. Gradusl improvement took place, and he can now walk fairly, bat with a limp. The right leg is still cold and wasted, but the knee-jerk is active. At the beginning of his attack there was some throat trouble, but two examinations for diphtheria gave a negative result. (Attended by Dr..Atchley and at Bristol General Hospital.) 